\title{
The Rationality of the Process of Theory Change in Science
}

\author{
Bisrat Tesfay \\ Department of Civics \& Ethical Education, Wolaita Sodo University, Wolaita Sodo, Ethiopia
}

\section{Email address:}

btdesalegn@gmail.com

\section{To cite this article:}

Bisrat Tesfay. The Rationality of the Process of Theory Change in Science. International Journal of Philosophy.

Vol. 8, No. 2, 2020, pp. 49-53. doi: 10.11648/j.ijp.20200802.14

Received: August 27,2019; Accepted: October 2, 2019; Published: June 17, 2020

\begin{abstract}
This article gives an ephemeral overview of the most influential views on the nature and process of change in science. Theory change in science is one of the most important issues in philosophy of science. Scientific theories are subject to change beyond space and time. There are various factors that lead theories change such as discomfort among the theories. In this paper, discussing how the rationality of science was related with its methods and methodologies, I tried to show that it was after Kuhn's work the Structure of Scientific Revolutions that the debate on theory choice becomes a central issue in philosophy of science. Following this the process in theory change in science can be deductive and inductive or rational and non-rational. According to the account of Kuhn's scientific change there are four steps in the process of scientific change; the predominant one is normal science, anomalies, crisis and finally a new phase of normal science. Then I discussed some of the philosophers who criticize Kuhn's work Structure of Scientific Revolutions, particularly popper's criticism on Kuhn; in this regard I also forwarded Kuhn's response for his critics. Finally I critically compared Kuhn's and Popper's ideas on the evolution of science.
\end{abstract}

Keywords: Falsification, Verification, Scientific Revolutions, Paradigm, Normal Science, Rational Change

\section{Introduction}

The history of science shows us that the already accepted scientific theories has been criticized, challenged and eventually become old scientific theories when they are replaced by the new ones. But the rationality of this process of scientific theory change depends on the method, for instance, whether context of discovery or context of justification adequate for understanding the rational process of scientific theory change. Of course, the rationality of this process of scientific theory change is a central issue in contemporary philosophy of science and I attempted to display clear clarification of "how" and "when" the debate on the rationality of this scientific theory change becomes.

This paper aims to show Kuhn's and Popper's response to the question that 'is a theory change in science a rational process?' It also discusses the common ideas and fundamental differences between them towards this question.

Science is a rapidly changing activity, but the rationality of its process depends on its methods. Some theories in science depend on local historical events without any justification but some others justified by scientific community. The rationality of science was related with its methods and methodologies, which mean that theory change in science, may be rational or irrational process based on method that used to approve the new theory and let down the old one. So, the later justified one is rational for me and the first one is irrational. For instance, Popper's view on the rationality of scientific theory change is not primarily based on rules of induction but depends on luck, ingenuity, and the purely deductive rules of critical argument [11].

Some others believe that the success or rationality of science depends on induction rules of argument. However, Kuhn comes up with a different conception of the rationality of science.

The impact Kuhn's structure of scientific revolution has been highly controversial, provoking some of the worst disagreements and the most heated debates among philosophers as to the character of scientific knowledge and its patterns of growth [12].

The debate on theory choice or rationality of theory change in science becomes a central issue in philosophy of science after Kuhn's work the Structure of Scientific Revolutions (SSR).

Kuhn's SSR, implies that if the paradigm has been subject 
to criticism and if a crisis happens, however and if a new paradigm is adopted by the scientific community, then a "revolution" or "paradigm shift" has occurred. Thus, for Kuhn when a revolution occurs the old paradigm is replaced wholesale. So this process of adoption or rejection of paradigm is refers to scientific revolution.

Therefore, it is after this work that the debate about theory change has been a central issue in contemporary philosophy of science. Because this work presented a radically different way of thinking about scientific methodology and knowledge, and it changed the practice of history of science. In this regard Kuhn argued that many scientists' accounts of the history of their subject considerably simplify and distort the real stories of theory development and change [7].

However, his work was criticized by some of his earlier readers; the critique accuse Kuhn for making science completely non-rational process characterized by dogmatic faith to paradigm in normal periods and unexpected 'conversion experiences' in revolutionary periods.

Kuhn was upset for the critics of the first edition of his work Structure of Scientific Revolution, non-rationality activity. Following this debate for the rationality of science becomes a central issue in philosophy of science. However, in a Postscript to the second edition of Structure of Scientific Revolution published in 1970, Kuhn attempt to show the rationality of science with certainty and to offer a more realistic, historically accurate picture of how science actually develops. So, Kuhn's primary aim of his second edition of Structure of Scientific Revolution is nothing other than clarification. This involves, he was not attempting to show that science was irrational, but rather to provide description of what scientific rationality involves. In this regard some thinkers claimed that Kuhn's Postscript is not a clarification of his work rather it is turn- a retreat from his original position. As far as I understand the point, this criticism seems to me simply abnormality and I agree with what Samir Okasha said, that the postscript shade a light or explain in denying the charge that he had described paradigm shift as non-rational.

One important clarification or point of a postscript is that "in rebutting the charge that he had portrayed paradigm shift as non-rational, Kuhn made the famous claim that there is 'no algorithm' for theory choice in science" [11].

According to Kuhn "algorithm" is a set of rules that employed us to give or compute the answer to particular question. In addition to this algorithm for theory choice in science is a set of rules that employed us to know which theory we should have to choose from the two computing theories, which one is the best or superior and which one is not.

In essence positivists believe there is algorithm for theory choice in science as a principle. But Kuhn denies this algorithm for theory choice in science, in this sense he believed that instead of algorithm for theory choice in science, subjective judgment or scientific common sense is better for theory choice, which theory of science is superior and which one is not [6].

In this regard the main question that has to be raised is the question of rationality or is theory change in science a rational process?

In this regard the question of rationality in theory change for the positivists implies that the rationality for theory change depends on the existence of "algorithm". This means according to the positivist algorithm or set of rules plays a pivot role in theory choice in science and it is the only rational way to proceed is to apply algorithm or rules for theory choice.

Popper critically criticizes Kuhn's work structure of scientific revolution particularly Kuhn's terms ' normal science'. Kuhn defined 'normal science as:

It is the activity of the non-revolutionary, or more precisely, the not-too-critical professional: of the science student who accepts the ruling dogma of the day; who does not wish to challenge it; and who accepts a new revolutionary theory only if almost everybody else is ready to accept it- if it becomes fashionable by a kind of bandwagon effect [6].

But for popper is not that kind, what normal science for him is a science that is falsifiable. In this regard he argues scientific statements must satisfy the criterion of falsifiability (or, equivalently, of refutability, testability); that is, they "must be capable of conflicting with possible, or conceivable, observations" [13]

According to Popper the main problem with Kuhn is that about scientific revolution. In this sense for Popper revolution is in permanence', on the other hand for Kuhn revolution in science is not in permanence rather it is exceptional and indeed, extra-scientific, and criticism is, in 'normal' times, anathema. This means the criticism of the old or superior theory and proposals of new theory is allowed in the rare moments of 'crisis'.

In this regard Kuhn argues that, the existence of crisis does not by itself transform a puzzle into a counter instance. There is no such sharp dividing line. Instead by proliferating versions of the paradigm, crisis loosens the rules of normal puzzle-solving in ways that ultimately permit a new paradigm to emerge [5].

Kuhn's, idea of scientific theory change also challenged by Imre Lakatos and in this regard Lakatos says Popper's scientific change or theory choice, the replacement of old theory with the new one is rational and it depends on logic of discovery. Through this regard Aristotle disclosed the rules of correct thinking were essential for the effective mastery of all sorts of knowledge. The basic form of logic was that of the syllogism, which deduced a characteristic of a subject by determining its membership in a class whose members shared that characteristic [2].

Whereas Kuhn's theory choice -paradigm shift from old to the new one is irrational, and primarily not based on rules of reason but within the realm of social or psychology of discovery. Thus, these debates on the rationality of science in theory change become central issues in philosophy of science. 


\section{Kuhn's Response for His Critics}

Kuhn claimed persuasion plays a major role in preferring or choosing one theory rather than another. However, this does not to mean that there are not any necessary or sound reasons for choosing one theory over the other. He also subject to the critics that is: "the adoption of a new scientific theory is an intuitive or mystical affair, a matter for psychological description rather than logical or methodological codification" [6].

On the contrary, he argues that some mystical aesthetics may play a pivot role for the success of new paradigm over the other. In addition to some mystical qualities he insisted some standards of reasons in philosophy of science which employed us to choose theory: accuracy, scope, simplicity, fruitfulness, and the like.

Rather Kuhn advised scientist to hold such values for theory choice. Thus, Kuhn did not deny the existence of good reasons for theory choice but he insists that such reasons constitute values to be used in making choice rather than rules of choice. Kuhn rejects the common assumptions of the logical empiricists that the aim of science is truth and that scientific rationality consists in applying some kind of logic to the relationship between a theory and straightforward assertions concerning the scientist's experience [3].

So, Kuhn's charge of irrationality is nothing but misinterpretation his work by others. Kuhn's response to the charge of relativism, according to him in one sense of the term he may be relativist; in a more essential one he is not. For Kuhn scientific development is basically evolutionary, which means that ideology gradually evolve to scientific theory. The origin of different theories is not too much different. In his attempt to show that he is not relativist he says:

I believe it would be easy to design a set of criteriaincluding maximum accuracy of predictions, degrees of specialization, number (but not scope) of concrete problem solutions-which would enable any observer involved with neither theory to tell which was the older, which the descendant. For me, therefore, scientific development is, like biological evolution, unidirectional and irreversible [6].

Kuhn was also criticized by Lakatos, and Lakatos said that Kuhn's conceptual framework... is socio-psychological but he deserves as normative for himself. In this regard, Kuhn do not give a focus for this critics and he said Lakatos do nothing other than employing a minor position in philosophical enterprise for himself. Kuhn claimed that Lakatos's position is socio-psychological.

Most critics of Kuhn's work have focused on the issue of normal science; that they claimed normal science does not exist and is uninteresting. In this regard Kuhn gives a response that the existence of normal science is the result of the existence of revolutions.

According to Kuhn if normal science did not exist or is non-essential, then the idea of revolution would be in difficulty. But later Kuhn agrees with his critics except Toulmin, that revolutions through criticism demand normal science no less than revolutions through crisis [6].

This discussion of normal science results another issues, theory change or the nature of change from one normal scientific tradition to another. In this regard Kuhn charges by the following points, irrationality, relativism and the defense of mob rule. But he rejects these all charges and he a respond to his critics.

This part is the body or main part of my paper and I am going to compare Popper and Kuhn based on the above issues and to identify the key similarities and differences concerning the defining characteristics of science and its process that how scientific knowledge evolves. As far as I understand them both philosophers have contributed important insights concerning the nature of science and the way in which scientific knowledge evolves even they were driven by different questions.

Kuhn claimed that on the historical process by which ideology can evolve into science but for Popper ideology and scientific theories are somewhat different and only the second one is cumulative in generating knowledge. Thus, both men have a major role or contribution to modern philosophy of science. The central issue that made both men different lies on the issues of scientific test. The primary significance of scientific test for Kuhn is just to increase the truth of the theory, but for Popper the truth or the validity of a theory is realized by falsification. In this regard both recognized the necessity of testability for science.

There is a little difference between both men on the issue of the demarcation between ideology and scientific theories. According to Popper, ideology and scientific theory is too much different and valid or cumulative knowledge is obtained from the scientific theory rather than ideology. In this regard Kuhn goes beyond what Popper already said, focusing on the historical process Kuhn claimed that ideology can gradually evolve in to science. Thus, according to Popper, a scientific theory must involve the following qualities. It must rule out specific possible occurrences, be falsifiable, and reliable to predict future events.

Regarding to the theory choice, the replacement of the old theory by a new and better theory both men has their own similarities and differences. Popper and Kuhn agree that there is no objective criterion for truth, but Kuhn takes this to mean that truth plays no role at all in theory appraisal and theory choice, while Popper maintains that truth plays the role of a regulative idea [4].

And different thinkers commented on this issue, for instance, L. Pearce Williams commented on the critical disagreement between Kuhn and Popper on this issue or scientific revolution. According to him:

Popper's science is basically and constantly potentially on the verge of revolution. A refutation, at least if it is big enough, constitutes such a revolution. But on the other hand, Kuhn argues the most of the time devoted to the pursuit of science is what he calls "normal " science- that is problem solving and hence for him scientific revolution is a long time event and occurs only rarely because most people are not 
trying to refute current theories [6].

Both men believed when a revolution raised in science the selection of the competing theories is maintained by scientific community. But the matter is how the 'fitness' resolute. Popper believed it is by means of the uniquely scientific testing process that selects out those hypotheses which fail to survive attempts to refute them. Kuhn believed that it is, instead, by established procedures of verification. "Verification," he said, "is like natural selection: it picks out the most viable among the actual alternatives in a historical situation.” (J. Ladyman) But exactly what did Kuhn mean by verification and how does he see it operating in the selection process? To verify means to confirm the truth of a proposition; that is, the accuracy with which it reflects reality.

Popper believes that before the old theory replaced by a new one, the new theory must solve the problems as well as its predecessor did and it should allow the deduction of predictions which do not follow from the old theory. Indeed for him these remarks ensure the rationality of scientific change and the remarks are not merely ensure the rationality of scientific progress but according to him the two remarks are also important or employed us to distinguish ideology from science.

\section{My Critical Remark}

My argument with the rationality of the process of theory change in science in some point is different from Popper's perspective. According to my understanding, the rationality of theory change in science is ultimately concerned with the acceptance of the theory by the community, because, if the old theory of science is replaced by the new one, I would say it is by default rational. When I say this, merely the inferential process of an argument on the process of theory change in science is not sufficient enough in itself. For instance, the old theory of science may be deductive, whereas the new one is inductive but accepted by the community as problem solving, and this process of theory choice in science is rational.

In addition to this, I appeal to Kuhn's argument on the theory choice in science. He is right when he say, there is "no algorithm" or rule which employed us to examine the rationality of the process of theory change in science. As I have explained above, the rationality of theory choice not merely determined by its logical reasoning as Popper argued. When an old theory in science faces a problem and crises, a revolution would be occurred and then the old one will be replaced by the new theory. However, the new raised theory must necessarily solve the problems faced in the old one and accepted by the community.

Accordingly, I would say, our concern with regards to the process of the theory choice in science is not merely about inferential process in its argument but whether it solves a problem faced on the old theory or it is accepted by the community. However, I don't mean that logical reasoning and methodology is not useful to identify a new theory, but it is not significant indicator of science merely in itself. This implies that our target should look towards the two important principles of theory choice in science. Therefore, the consideration of the above listed points is the apparatuses to determine the rationality of the process of theory change in science.

\section{Conclusion}

In this paper I forwarded some critical claims, these are: 1. the rationality of theory choice in science was related with its methods and methodologies, which mean that theory change in science, may be rational or irrational process based on method that we used to approve the new theory and let down the old one. 2. There was also a critical debate on the rationality of theory choice. This debate was known and becomes a central issue in philosophy of science after Kuhn's work, the structure of scientific revolutions. It is because Kuhn gives an important influence in his work the Structures of Scientific Revolution about theory change, because this work presented a radically different way of thinking about scientific methodology and knowledge, and changed the practice of history of science. In this regard Kuhn argued that many scientists' accounts of the history of their subject considerably simplify and distort the real stories of theory development and change. 3 . Kuhn charges by the following points, irrationality, relativism and the defense of mob rule. 4. Popper and Kuhn were interested to view their models as radically contradictory in their epistemological premises and practical implications. However, it is not too much difficult to detect or to identify key similarities that may point to encouraging complementarity concerning the defining characteristics of science and its process or evolution that lies between them.

\section{References}

[1] Alex Rosenberg, Philosophy of Science-A contemporary introduction, third edition 2012.

[2] Applebaum, W. (2005). The Scientific Revolution and the Foundations of Modern Science. London: Greenwood Press.

[3] Bokulich, W. J. (2015). Kuhn's Structure of Scientific. Switzerland: (C) Springer International Publishing.

[4] Gattei, S. (2009). Karl Popper's Philosophy of Science: Rationality Without Foundations. New York: Routledge.

[5] Kuhn, T. S. (1996). Structure of Scientific Revolution. Chicago: University of Chicago Press.

[6] Musgrave, I. L. (1970). Criticism and the Growth of Knowledge. London: Cambridge University Press.

[7] Ladyman, J. (2002). Understanding Philosophy of Science. NewYork: Taylor \& Francis e-Library.

[8] 1993 "Kuhn's Changing Concept of Incommensurability." The British Journal for the Philosophy of Science 44 (1993): 759 774. Reprinted in Sankey (1997), 21-34. 
[9] Martin Curd, and J. A. Cover, Philosophy of Science: The central issues. New York.

[10] Popper, Karl Raimund. 2002a. Conjectures and Refutations: The Growth of Scientific Knowledge. Psychology Press.

[11] Samir Okasha, Philosophy of Science: A very short introduction, Oxford University Press).

[12] (1987). Logic, Methodology, and Philosophy of Science VII, Moscow, 1987 I edited by Jens Erik Fenstad, Ivan T. Frolov, Risto Hilpinen.
[13] Stathis, Psillos and Martin, Curd (2008). The Routledge Companion to Philosophy of Science (eds). New York: Taylor \& Francis e-Library, 2008.

[14] Vickers, Brian, ed. Occult and Scientific Mentalities in the Renaissance. Cambridge: Cambridge University Press, 1984.

[15] Westman, Robert and J. E. McGuire. Hermeticism and the Scientific Revolution. Los Angeles: Clark Memorial Library, 1977. 